\title{
$\mathrm{OFDM} / 64 \mathrm{QAM}$ 방식의 모뎀 설계
}

\section{Study on the Improvement of OFDM/64QAM Modem}

\author{
박진수* \\ Jin-Soo Park \\ 요 약
}

본 논문에서는 $2.4 \mathrm{GHz}$ 대역에서 적용 가능한 무선 LAN용 모뎀을 설계•제안하였으며, 실제 $\mathrm{PCB}$ 로 제작되 어 데이터 송수신을 확인하였다. 본 논문에서 제안하고 있는 모뎀의 경우, 메인 프로그램을 처리하기 위해 기

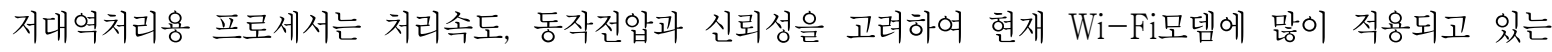
Ralink사의 RT2870을 사용하였다. RT2870은 현재 무선 LAN의 표준을 완벽히 지원하며, 다양한 변조방식을 지원하고 있으며, $2.4 \mathrm{GHz}$ 와 $5 \mathrm{GHz}$ 대역을 모두 지원하는 칩이다. 또한 본 논문에서는 출력된 변조신호를 $2.4 \mathrm{GHz}$ 대역의 무선으로 전송하기 위하여 RF 처리용 칩인 RT2850을 적용하였으며, $40 \mathrm{MHz}$ 대역을 사용하여 $2.422 \sim 2.462 \mathrm{GHz}$ 의 무선 대역을 점유하도록 설계하였다. 제안된 모뎀은 저렴한 비용으로 향후 $2.4 \mathrm{GHz}$ 대역의 무선인터넷 모뎀으로의 사용이 가능하며, 본 설계를 바탕으로 $\mathrm{Wi}-\mathrm{Fi}$ 기반의 개인통신기기 또는 무선 기반 POS 시스템 개발에 적극 활용이 가능하다. 특히, 안드로이드 기반 개인용 무선단말기의 모뎀으로 적용이 가능하며 이를 이용하여 다양한 제품으로의 확대가 가능할 것으로 기대된다.

\section{Abstract}

In this paper, we propose a wireless modem, which used OFDM/64QAM method and the ISM band with $2.4 \mathrm{GHz}$ radio frequency. In this paper proposed the case of a modem, the main program to process the baseband processor, processing speed, operating voltage, and reliability should be ensured. So we have designed with Ralink's RT2870, witch was used for Wi-Fi solution. The RT2870 provides full support for wireless LAN standard, and supports various modulation formats, $2.4 \mathrm{GHz}$ and $5 \mathrm{GHz}$ bands, both of which support chip. In this paper, we also output the modulated signal transmitted wirelessly to the $2.4 \mathrm{GHz}$ band RF RT2850 chip processing was applied and using $40 \mathrm{MHz}$ band $2.422 \sim 2.462 \mathrm{GHz}$ wireless bands were designed to occupy. By applying bi-directional transmission between wireless transmitter and receiver, it can be effectively connected with any kinds of wireless LAN with $2.4 \mathrm{GHz}$ ISM band. Therefore it could economically be used as peripheral equipments for POS system or personal wireless device based on Android platform.

Key words : OFDM, M-QAM, 64QAM, Wi-Fi, Wireless LAN

I. 서 론

21세기는 정보통신분야의 초고속 발전에 힘입어 정보기반산업으로의 비즈니스 확산이 빠르게 이루어

* 청주대학교 전자정보공학부(Cheongju University)

· 제1저자 (First Author) : 박진수

· 투고일자 : 2012년 2월 10일

· 심사(수정)일자 : 2012년 2월 10일 (수정일자 : 2012년 2월 25일)

· 게재일자 : 2012년 2월 28일 
지고 있는 실정이며, 특히 개인용 휴대전화나 인터넷 과 같은 유무선 통합 솔루션이 개발되면서 장소와 시 간에 상관없이 실시간의 정보교류 및 검색이 가능해 지고 있다.

이러한 정보통신분야의 기술발전에 힘입어 최근 에는 무선통신 인프라를 이용한 무선인터넷(Wi-Fi)접 속망이 활발하게 구축되고 있으며, 특히 4세대 이동 통신의 기술과 접목하여 다양한 무선서비스제공이 이루어지고 있다. 이러한 다양한 무선서비스제공을 위해 기존의 $802.11 \mathrm{a}$ 표준안이 $802.11 \mathrm{n}$ 으로 개선되었 으며, 이를 바탕으로 실시간 멀티미디어 서비스가 가 능해지고 있다. 이를 반영하듯 초고속 무선접속기술 의 변복조기술에 대한 연구가 활발히 진행되고 있으 며 그 중 하나가 직교주파수분할 [OFDM/Orthogonal Frequency Division Multiplexing]방식이다. OFDM은 고속의 송신 신호를 다수의 직교(Orthogonal)하는 협 대역 반송파로 다중화시키는 변조 방식을 말한다.

현재 OFDM은 4세대 이동통신 및 802.11a, $802.11 \mathrm{~g}$ 등에 이용되고 있는 기술이며, 특히 64QAM 기술을 적용함으로써 고속의 무선데이터 통신이 가 능하도록 발전하고 있다.

이에 본 논문에서는 $2.4 \mathrm{GHz}$ ISM 대역에 적용 가 능한 무선인터넷용 모뎀을 설계하였다. 제안된 시스 템은 저렴한 비용으로 향후 $2.4 \mathrm{GHz}$ 대역의 무선인터 넷 모뎀으로의 사용이 가능하며, 본 설계를 바탕으로 Wi-Fi기반의 개인통신기기 또는 무선 기반 POS 시스 템개발에 적극 활용하도록 하는데 그 목적이 있다.

\section{OFDM의 기본원리}

고속의 전송률을 갖는 데이터열을 낮은 전송률을 갖는 많은 수의 데이터열로 나누고, 이들을 다수의 부반송파를 사용하여 동시에 전송하는 것이다. 즉, OFDM은 데이터열을 여러 개의 부채널(Sub-channel) 로 동시에 나란히 전송하는 다중 반송파 전송방식의 특별한 형태로 본다. 따라서 OFDM 기법은, 1개 채 널의 고속의 원천 데이터열을 다중의 채널로 동시에 전송한다는 측면에서는 다중화 기술이며, 다중의 반 송파에 분할하여 실어 전송한다는 측면에서는 일종
의 변조 기술이다. 각 부반송파의 파형은 시간축상으 로는 직교(Orthogonal)하나, 주파수축상에서는 겹치 게(Overlap)된다. 이것을 그림1로 나타내면 다음과 같다.

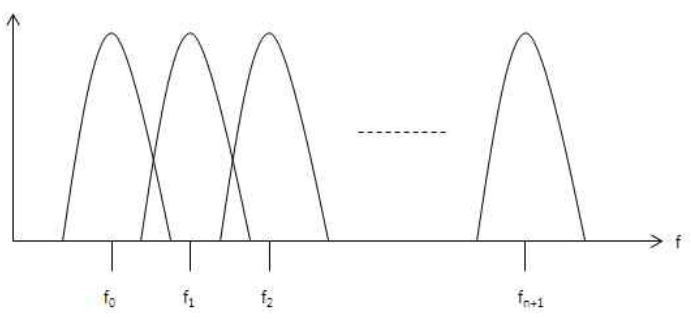

그림 1. OFDM 신호의 스펙트럼 특성

Fig. 1. Spectrum of OFDM signal

현재 OFDM기술은 다양한 분야에서 활용되고 있 는데 $802.11 \mathrm{a}, 802.11 \mathrm{~g}, 802.16$ 등의 무선 LAN 분야와 디지털방송중 유럽식(DVB), 미국식(ATSC), 일본식 모두 OFDM을 채용하고 있다. 또한 이동통신분야에 서는 4세대 이동통신이 OFDM을 기반으로 하고 있으 며, 이외에도 HDSL, ADSL 그리고 무선 ATM 같은 방식에 적용하기 위한 연구가 활발히 이루어지고 있 다[1].

QAM방식은 진폭천이방식(ASK)과 위상천이방식 (PSK)의 결합으로 볼 수 있다[2].

\section{2.4GHz 대역의 모뎀 설계}

\section{3-1 시스템 아키텍처}

본 논문에서 설계한 $2.4 \mathrm{GHz}$ 대역의 무선 모뎀의 기본적인 블럭도를 그림 2에 나타내었다.

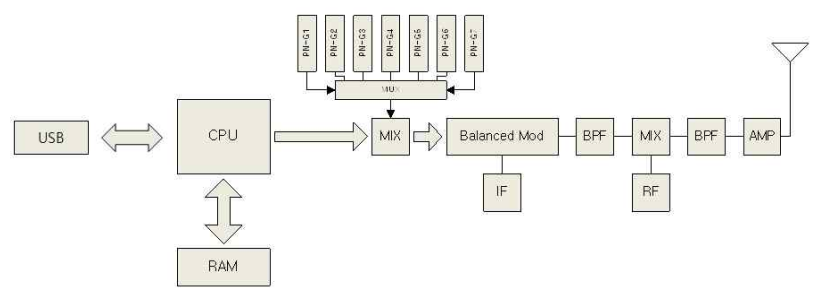

그림 2. $2.4 \mathrm{GHz}$ 무선 모뎀 기본 블록도

Fig. 2. Bolck diagram of $2.4 \mathrm{GHz}$ wireless modem 
그림2와 같이 본 논문에서 제안하고 있는 모뎀의 경우, Ralink사의 기저대역 프로세서인 RT2870을 사 용하였다. RT2870는 $802.11 \mathrm{a} / \mathrm{b} / \mathrm{g} / \mathrm{n}$ 등 현재 무선 LAN 의 표준을 완벽히 지원하며 특히, RT2870칩은 고속 의 무선데이터 전송을 가능하게 하기 위해 $64 \mathrm{QAM}$, $16 \mathrm{QAM}, \mathrm{QPSK}, \mathrm{BPSK}$ 등의 다양한 변조방식을 지원 하고 있으며, $\mathrm{RF}$ 단의 칩셋에 따라서 $2.4 \mathrm{GHz}$ 대역과 $5 \mathrm{GHz}$ 대역을 모두 지원하는 칩이다[3].

본 논문에서는 일반적으로 많이 사용되고 있는 $2.4 \mathrm{GHz}$ 대역을 사용하기 위하여 RT2850을 적용하였다. RT2850은 40MHz 대역을 사용하며 2.422 2.462GHz의 무 선대역을 점유하도록 설계되어 있다.

\section{3-2 2.4GHz 모뎀의 하드웨어 설계}

그림 2에서 메인프로그램을 처리하기 위해 사용된 기저대역처리용 프로세서는 처리속도, 동작전압과 신뢰성을 고려하여 현재 Wi-Fi 모뎀에 많이 적용되고 있는 Ralink사의 RT2870을 이용하였으며, PC에서 전송하고자 하는 데이터의 원활한 인터페이스 설계 를 위하여 USB 포트를 탑재하였다.

현재 국내의 주파수 할당 현황을 보면 정부의 허 가없이 자유로이 사용할 수 있는 ISM(Industrial Scientific and Medical)주파수 대역이 할당되어 있다. ISM대역은 원래 비면허로 약한 전계강도를 이용하 여 산업, 과학 및 의료용으로 할당된 대역이며, 무선 LAN에서 사용이 가능하다.

본 논문에서 제안한 모뎀의 기본사양을 정리하면 다음과 같다.
표 1. 모뎀 기본사양

Table 1. Modem specification

\begin{tabular}{|l|l|}
\hline \multicolumn{1}{|c|}{ 항 목 } & \multicolumn{1}{c|}{ 사 양 } \\
\hline Baseband-Processor & RT2870 \\
\hline RF CHIP & RT2850 \\
\hline 데이터 I/O & USB2.0 \\
\hline 데이터 전송속도 & 최대 $300 \mathrm{Mbps}$ \\
\hline 채널대역폭 & $40 \mathrm{MHz}$ \\
\hline 송수신주파수 & $2.422 ~ 2.462 \mathrm{GHz}$ \\
\hline 최대출력 & $+17 \mathrm{dBm} \pm 1.5 \mathrm{dBm}$ \\
\hline 입력전원 & $5 \mathrm{~V}$ \\
\hline 확산방식 & 직접확산 \\
\hline 변조방식 & $64 \mathrm{QAM}, 16 \mathrm{QAM}$ \\
& $\mathrm{QPSK}, \mathrm{BPSK}$ \\
\hline 안테나 & 칩안테나 \\
\hline 수신감도 & $-74 \mathrm{dBm} \pm 2 \mathrm{dBm}$ \\
\hline
\end{tabular}

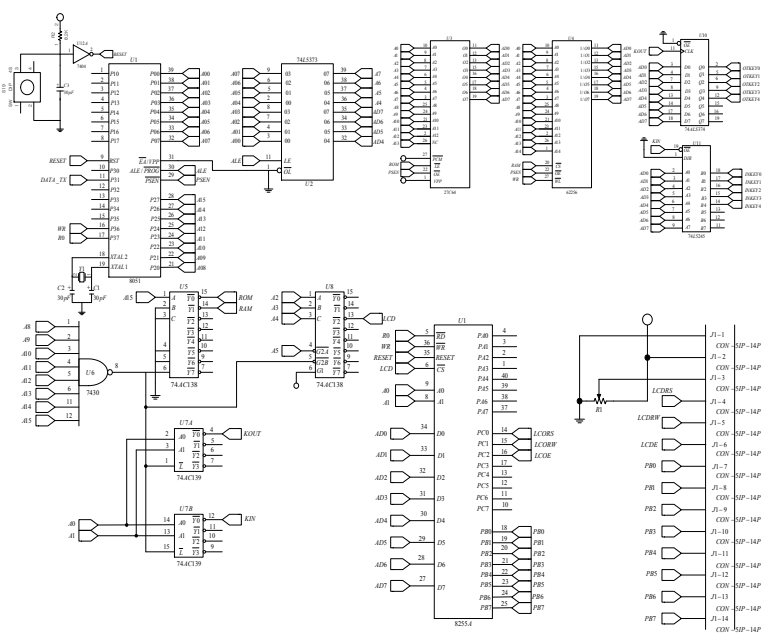

그림3. RT2870을 이용한 디지털회로부

Fig. 3. Digital circuit with RT2870

그림 3은 RT2870을 이용한 기저대역의 디지털회로 부이다. 전송하고자 하는 데이터는 USB 포트를 이용 해 RT2870으로 입력되고 내부에서 이진 binary 형태 로 코딩된 후 디지털 변조를 위하여 내부 $\mathrm{D} / \mathrm{A}$ 변환기에 인가된다. 인가된 데이터는 내부 레지스터의 설정에 따라서 64QAM, 16QAM, QPSK, 또는 BPSK 변조기로 인가되어 $40 \mathrm{MHz}$ 대역의 변조신호로 출력된다.

출력된 변조신호는 무선으로 전송하기 위하여 RF 처리용 칩인 RT2850으로 인가되고 $2.442 \mathrm{GHz}$ 신호와 
내부 믹싱되어 2.422 2.462GHz대역의 신호로 변조되 게 된다. 변조된 신호는 자유공간으로 방사되기 위한 충분한 파워를 갖게 하기위해 내부의 RF Amp를 통 화한 후 칩안테나를 이용하여 자유공간에 방사된다.

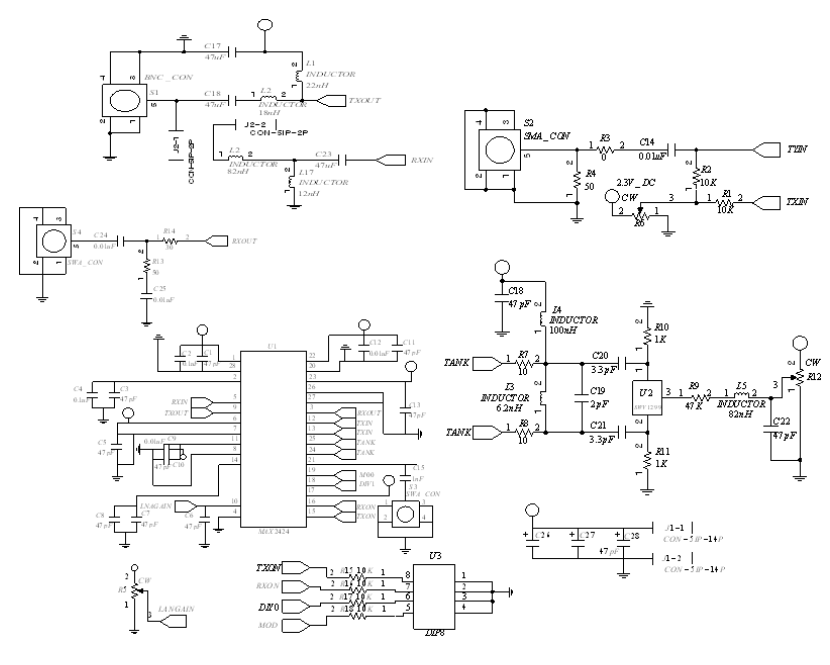

그림 4. RF 송수신부

Fig. 4. RF Transceiver

자유공간에 방사된 신호는 그림 4와 동일한 구조 를 갖는 수신기의 칩안테나에 수신되고 RT2850 내부 의 LNA와 주파수 Down-Converter 및 디지털 복조회 로를 거쳐 수신된 후 최종적으로 수신부의 기저대역 프로세서인 RT2870으로 입력되어 수신데이터로 인 식된다. 이때 자유공간을 통과한 전파는 각종 페이딩 이나 위상, 진폭잡음 등에 의해 심하게 훼손되며 데 이터에 에러를 발생시키는 원인이 되기도 한다.

그림 5 는 회로도를 이용하여 제작된 $\mathrm{PCB}$ 의 단면 도이다. $\mathrm{PCB}$ 는 $\mathrm{RF}$ 특성 및 부품의 실장도를 고려하여 6층 $\mathrm{PCB}$ 로 제작되었다.

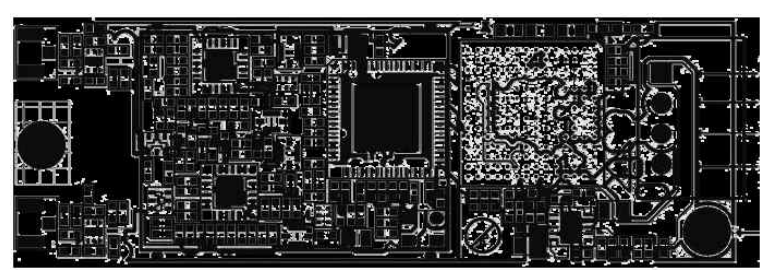

그림 5. 2.4GHz 모뎀의 $\mathrm{PCB}$

Fig. 5. PCB of $2.4 \mathrm{GHz}$ Modem

그림 6 은 제작된 제품의 실사진이다. $\mathrm{PCB}$ 의 전면 부와 후면부에 각각 SMT부품이 실장 되어있다.

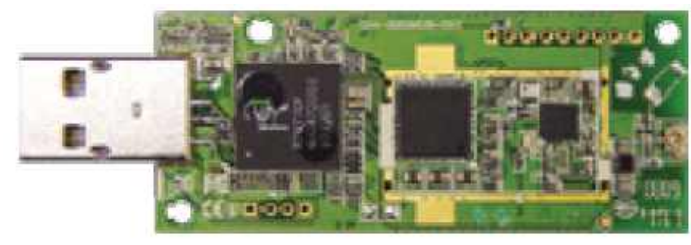

그림 6 . 제작된 $2.4 \mathrm{GHz}$ 모뎀

Fig. 6. Implemented Modem

그림 7은 본 모뎀을 이용하여 양방향 데이터를 송 수신 데이터의 실제 파형이다. 그림에서 알 수 있듯 이 송신한 데이터가 일정 시간 지연 후 수신데이터로 에러없이 수신된 것을 알 수 있다.

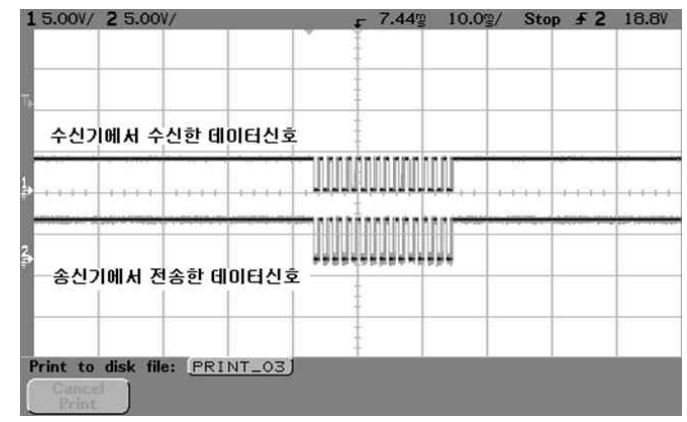

그림 7. 송수신 데이터 비교

Fig. 7. Comparison with TX and RX data

\section{$\mathrm{IV}$. 결 론}

본 논문에서는 $2.4 \mathrm{GHz}$ 대역에서 적용 가능한 무선 LAN용 모뎀을 설계•제안하였으며, 실제 $\mathrm{PCB}$ 로 제작 되어 데이터 송수신을 확인하였다.

제안된 모뎀은 저렴한 비용으로 향후 $2.4 \mathrm{GHz}$ 대역 의 무선인터넷 모뎀으로의 사용이 가능하며, 본 설계 를 바탕으로 Wi-Fi기반의 개인통신기기 또는 무선 기 반 POS 시스템 개발에 적극 활용이 가능하다.

특히, 안드로이드 기반 개인용 무선단말기의 모뎀 으로 적용이 가능하며 이를 이용하여 다양한 제품으 로의 확대가 가능할 것으로 기대된다.

\section{감사의 글}

이 논문은 2010학년도 청주대학교 산업과학연구 소가 지원한 학술연구조성비(특별연구과제)에 의해 연구되었음. 


\section{참 고 문 헌}

[1] http://www.ieee.org

[2] Bernard Sklar, "Digital Communications Fundamentals and Applications", Prentice Hall, pp.667, 2001.

[3] http://www.ralinktech.com

[4] Joseph J. Carr, "RF CIRCUIT DESIGN", McGraw-Hill, 2001.

[5] Jacques van Wyk, "Bit error probability for a M-ary QAM OFDM-based system", IEEE, 2007.

[6] Elena Costa, "M-QAM-OFDM System Performance in the Presence of a Nonlinear Amplifier and Phase Noise", IEEE Transaction on Communications Vol.50 No.3, March 2002.

[7] Ana Garcia Armade, "Understanding the Effects of Phase Noise in Orthogonal Frequency Devision Multiplexing(OFDM)", IEEE Transacion on Broadcasting Vol.47, No.2, June 2001.
박 진 수 (朴鎭秀)

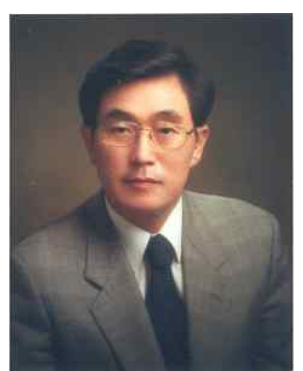

1975년 2월 : 한양대학교 전자 공학과(공학사)

1977년 2월 : 한양대학교 전자 공학과(공학석사)

1985년 2월 : 한양대학교 전자 공학과(공학박사)

1978년 3월 현재 : 청주대학교 전자정보공학부 교수 관심분야 : 이동통신, 오류정정, 대역확산통신 